\title{
Macro-Microscopic Atlas on Heartwood of Santalum album L. (Sandalwood)
}

\author{
Susikumar Sundharamoorthy*, Nartunai Govindarajan, Arunachalam Chinnapillai, Ilavarasan Raju
}

\section{Susikumar \\ Sundharamoorthy*, Nartunai Govindarajan, Arunachalam Chinnapillai, llavarasan Raju}

Captain Srinivasa Murthy Regional Ayurveda Drug Development Institute, CCRAS, Govt. of India, Chennai - 600 106, Tamil Nadu, INDIA.

Correspondence

Susikumar Sundharamoorthy

Botany/Pharmacognosy, Captain Srinivasa Murthy Regional Ayurveda Drug Development Institute, CCRAS, Govt. of India, Arignar Anna Hospital Campus, Arumbakkam, Chennai-600106, Tamil Nadu, INDIA.

Phone No: +91-9003801125

E-mail: susikumarmsc@gmail.com

History

- Submission Date: 09-02-2018;

- Review completed: 14-03-2018

- Accepted Date: 03-05-2018

DOI : 10.5530/pj.2018.4.122

Article Available online

http://www.phcogj.com/v10/i4

Copyright

(C) 2018 Phcog.Net. This is an openaccess article distributed under the terms of the Creative Commons Attribution 4.0 International license.

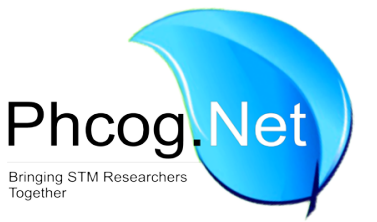

\begin{abstract}
Background: Santalum album L. (Fam. Santalaceae) is a small evergreen tree distributed in South India mainly on the Deccan plateau, especially in Mysore and Tamil Nadu. The heartwood is highly prized and medicinally useful; Santalum album is one of the ingredients in many Ayurvedic and Siddha formulations. Objective: The present study brings out macromicroscopic atlas on heartwood of medicinal plant Santalum album L. Materials and Methods: Sections and powder were observed and photographed under different magnifications with the help of Olympus BX51 Microscopic unit fitted with Olympus Camera. Results: Macroscopically odour and taste, microscopically tyloses, fibres, tailed pitted vessels, uni and biseriate medullary rays, brownish content and oil globules are the unique diagnostic characters reported. Conclusion: The finding of the present study is believed to be helpful in identifying the correct botanical source of the plant in crude form and also standardization of herbal formulation containing sandalwood as ingredient.

Key words: Sandalwood, Santalum album, Chandana, Macro-microscopic atlas, Pharmacognosy.
\end{abstract}

\section{INTRODUCTION}

Santalum album L. (Fam. Santalaceae) is a small evergreen tree about $18 \mathrm{~m}$. in height and $2.4 \mathrm{~m}$. in girth, distributed in South India mainly on the Deccan plateau, especially in Mysore and Tamil Nadu ${ }^{1}$ (Figure 1 A, B, C). The heartwood of sandalwood (Chandana) is used in hyperacidity, haemorrhoids, diarrhoea with blood, excessive thirst, vomiting, intrinsic haemorrhages, irritable bowel syndrome, hiccough, burning micturition etc., ${ }^{2,3}$ The heartwood of Santalum album is used in many Ayurvedic and Siddha formulations namely Ayaskrti, Asvagandhadyarista, Sarviradyasava, Arimedadi Taila, Baladhatryadi Taila, Marma Gutika, Candanasava, Candanadi Curna, Candanadi Taila, Tippilli Ney, Tekkamalli Thailam, Kumari Thailam. ${ }^{3-5}$

Sandalwood oil is esteemed all over the world and is highly prized in perfumery and cosmetics. The highest yield of sandalwood oil is from roots and lowest from the sap wood. The main and major (more than 90\%) constituent of sandalwood oil is santalol $\left(\mathrm{C}_{15} \mathrm{H}_{24} \mathrm{O}\right)$, a mixture of two isomers, $\alpha$-santalol and $\beta$-santalol. ${ }^{1,2}$ The other constituents reported are santene, nor-tricycloekasantalal, $\alpha$ - and $\beta$-santalenes, santenol, teresantenol etc., ${ }^{1,2}$

Botanically sandalwood (Santalum album L., Fam. Santalaceae) and Red sandalwood (Pterocarpus santalinus L.f., Fam. Papilionaceae) are belongs to different genus and family sharing the similar vernacular name sandal. In India, the wood of Erythroxylum monogynum Roxb. is perfumed with sandalwood oil and used as an adulterant and the wood of Mansonia gagei J.R. Drumm. is considered as substitute. ${ }^{1,2}$ Preparation of morphological, anatomical and powder microscopic atlas of heartwood of Santalum album have been undertaken to identify/authenticate the raw drug and also to standardize the Ayurvedic and Siddha formulations containing heartwood of Santalum album L. as ingredient in powder form and is reported in this paper.

\section{MATERIALS AND METHODS}

The heartwood samples of Santalum album L. was purchased from local market of Chennai. The heartwood of Santalum album was authenticated by Pharmacognosy department, Captain Srinivasa Murthy Regional Ayurveda Drug Development Institute, Arumbakkam, Chennai, India and the voucher specimens deposited (L/249 Wd 9) for future reference. Macro-morphological study was carried out by following the standard methods. ${ }^{8,9}$ The anatomical studies were carried by following standard procedures. ${ }^{9-11}$ For powder microscopic study the plant material after cleaning and drying properly, powdered and passed through sieve No. 80. The mounting and staining was carried out by standard methods. ${ }^{11-13}$ Sections and powder were observed and photographed under different magnifications with the help of Olympus BX51 microscopic unit fitted with Olympus camera. 


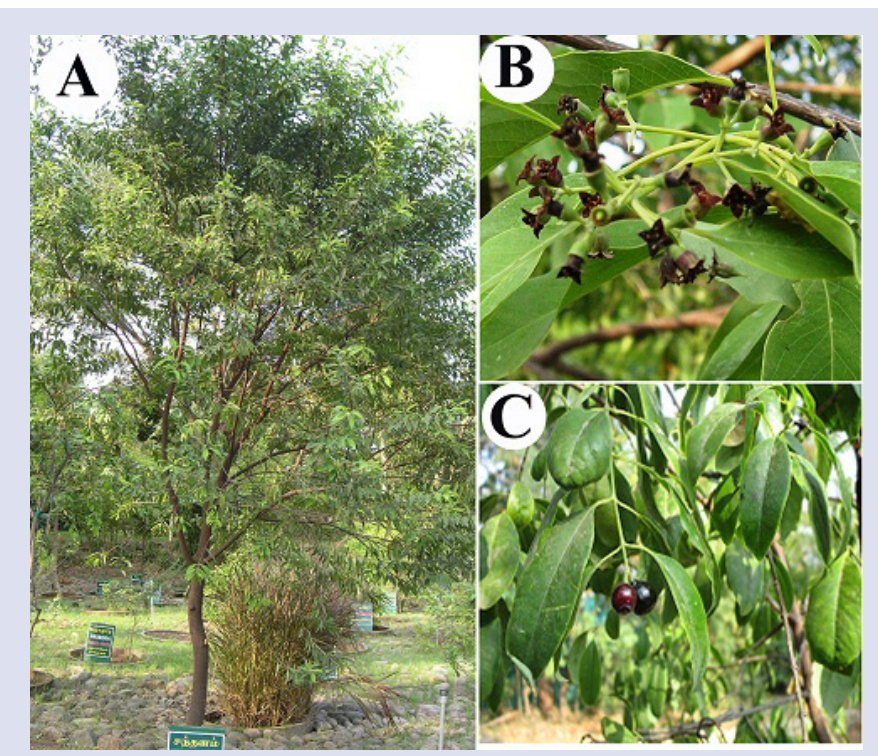

Figure 1: A, Habit; B, Flowering twig; C, Fruiting twig.

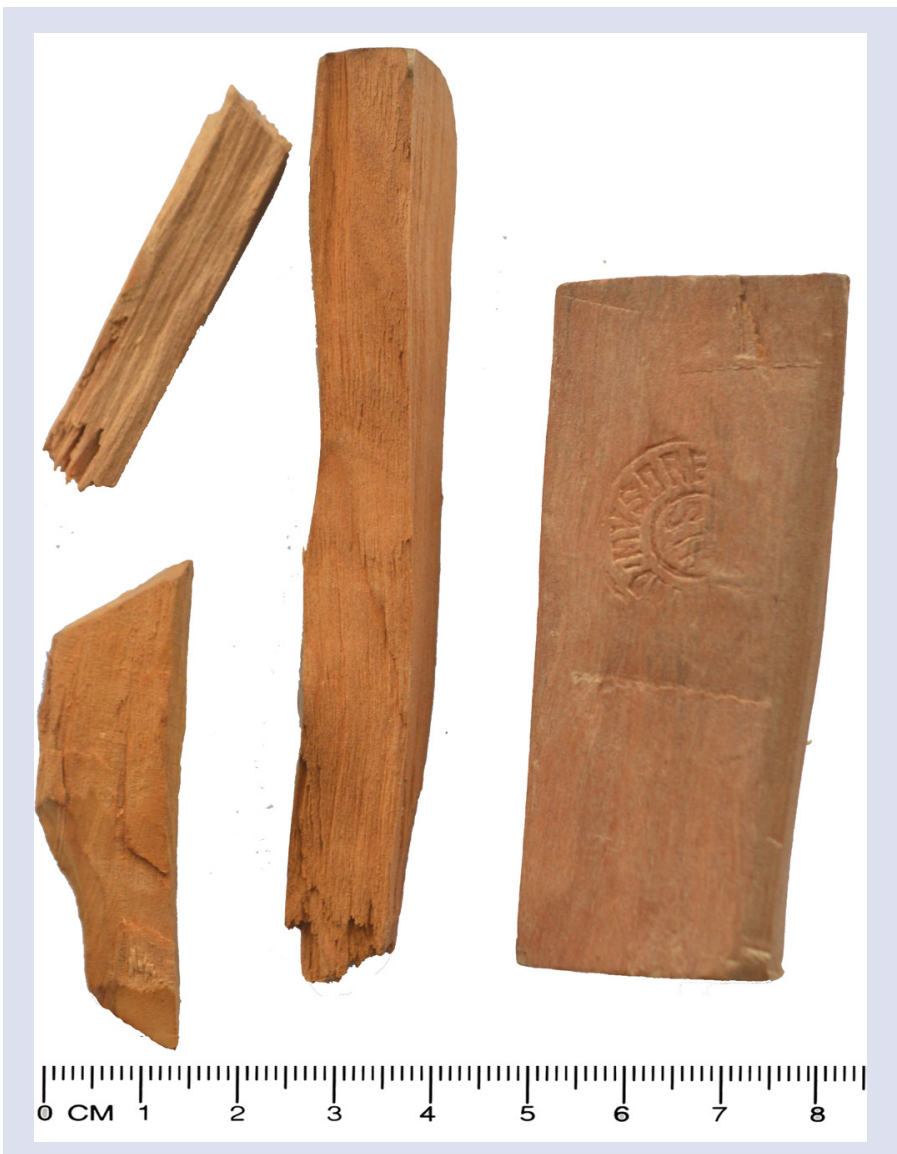

Figure 2: Dried cut pieces of heartwood.

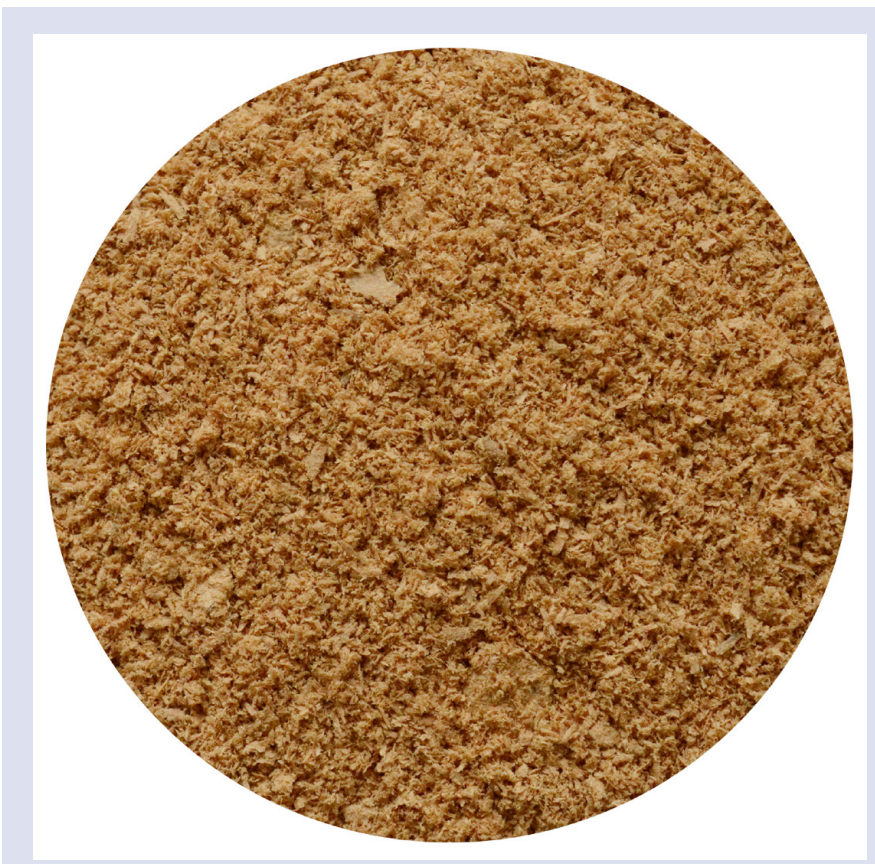

Figure 3: Powder of heartwood.

Table 1: Macroscopic characters of Heartwood of Santalum album L..

\begin{tabular}{cc}
\hline Macroscopical characters & Heartwood of Santalum album L. \\
\hline $\begin{array}{c}\text { Colour, Odour and Taste } \\
\text { Pale yellowish to yellowish-brown, odour } \\
\text { pleasant and characteristic; taste slightly bitter } \\
\text { and astringent. }\end{array}$ \\
Surface \\
Size and Shape \\
Longitudinally cut pieces 5 to $10 \mathrm{~cm}$ in length, \\
granular. \\
Texture and Fracture 4 cm in width and upto 1 to $3 \mathrm{~cm}$ in \\
thickness.
\end{tabular}

\section{RESULTS}

\section{Macroscopy}

The detailed macroscopic characters observed are reported in Table 1.

\section{Microscopy}

Transverse section of heartwood shows isolated vessels embedded with tylosis, thick walled wide lumen fibres embedded with brownish content, occupying the major portion of the wood; vessels are arranged in diffused pore, parenchyma mostly vesicentric, medullary rays uni and biseriate running almost straight and parallel, except when are adjacent to vessels get slightly bent (Figure 4 ).

\section{Powder microscopy}

Microscopically tylosis, fibres, tailed pitted vessels, uni and biseriate medullary rays, brownish content and oil globules are the unique diagnostic characters reported (Figure 5). 


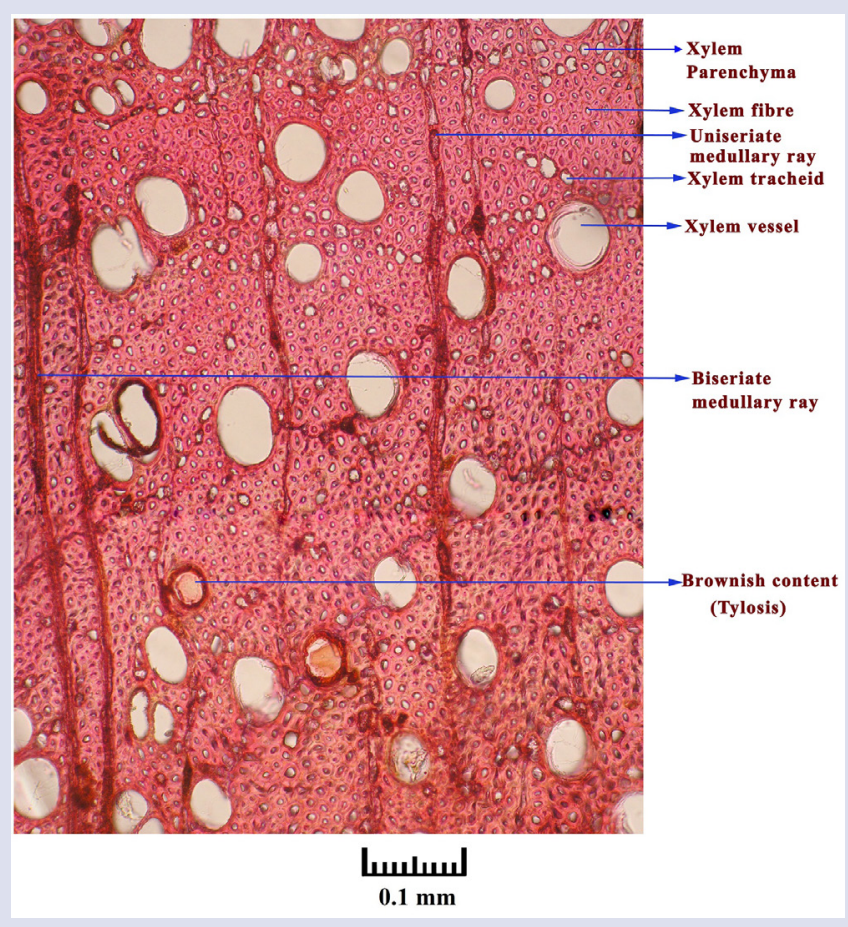

Figure 4: Transverse section of Santalum album L. heartwood.

\section{DISCUSSION}

Pharmacognostic characters of herbal drugs play an important role since particular macro-microscopic features are unique for each plant. The macroscopic and microscopic studies of the plant material should be the first and fundamental step to authenticate the botanical source. Morphology is the study of the description of the plant material. The plant anatomical studies deal with the structure of organisms, structure gross and minute, external and internal. ${ }^{6,7}$ Proceeding for chemical methods of standardization, preclinical and clinical evaluations will bear no value if authentic drugs are not used. Macro-microscopic evaluation is simple and cost effective.

In India, the wood of Erythroxylum monogynum is perfumed and used as an adulterant for Santalum album and the wood of Mansonia gagei is considered as substitute. ${ }^{1,2}$ The transverse section of Santalum album shows narrow medullary rays, the vessels are partly loaded with yellow resin. The sap wood is brighter yellow in colour, both vessels and medullary rays are less distrinct. The sap wood is scentless compared to heartwood due to less number of oil globules. ${ }^{12}$ The study sets the specific macromicroscopic protocols to establish identity of the crude drugs of the heartwood of Santalum album and also to standardize the Ayurvedic formulation containing sandalwood as ingredient.

\section{CONCLUSION}

Macro-microscopic Atlas on heartwood of Santalum album L. (Sandalwood) has been carried out and reported first time in this paper. Findings of this study may be used as atlas on quality standards of heartwood of Santalum album. Macroscopically odour and taste, microscopically tyloses, fibre, tailed vessels, uni and biseriate medullary rays, brownish content and oil globules are the unique diagnostic characters reported in Santalum album. The sap wood of sandal which is inferior in quality can be differentiated by the colour and odour morphologically and microscopically by less distinct medullary rays, vessels and oil globules. The study sets the

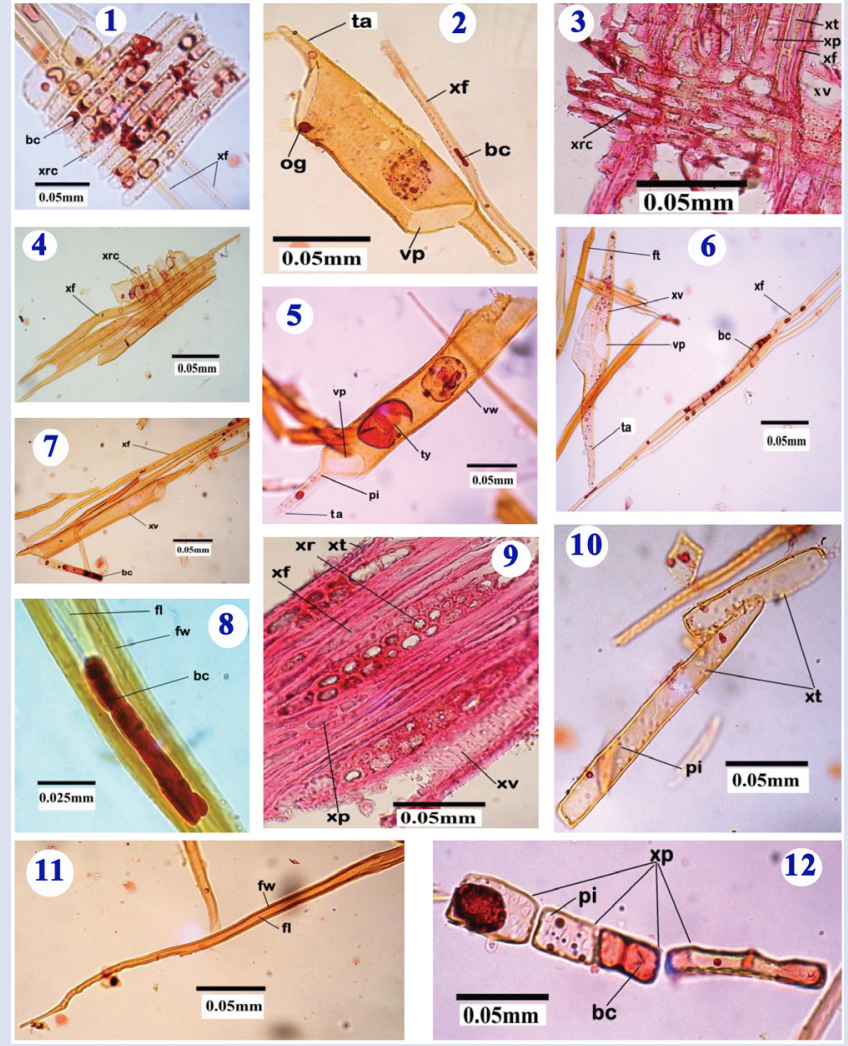

Figure 5: 1, Radially cut medullary ray crossing with fibre with brownish content; 2, Oil globule, tailed pitted vessel and fibre with brownish content; 3 , Radially cut xylem ray crossing with xylem vessel, fibre and tracheids; 4 , Radially cut xylem ray crossing with fibre; 5 , Tailed pitted vessel embedded with tylosis; 6 , Tailed vessel, fibre and fibre tracheid; 7, Fibre and tailed vessel; 8 , Fibre with brownish content; 9 , Tangential longitudinally cut xylem ray with xylem vessel, fibre, parenchyma and tracheids; 10, Tracheids; 11, Fibre; 12, Xylem parenchyma with brownish content.

specific macro-microscopic protocol to establish identity of the crude drug of the heartwood of Santalum album and also to standardize the Ayurvedic formulation containing sandalwood as ingredient.

\section{CONFLICT OF INTEREST}

The authors declare no conflict of interest.

\section{ABBREVIATIONS}

Fig. figure; $\mathbf{x v}$, xylem vessel; fw, fibre wall; fl, fibre lumen; $\mathbf{x r c}$, xylem ray cells; ta, tail; pi, pits; ty, tylosis; vw, vessel wall, fp, fibre pits; $\mathbf{f t}$, fibre tracheid; xf, xylem fibre; bc, brownish content; og, oil globule; $\mathbf{x t}$, xylem tracheid; xp, xylem parenchyma; $\mathbf{v p}$, vessel perforation.

\section{REFERENCES}

1. Anonymous. The Wealth of India, Raw materials, Vol.IX; Rh-So, National Institute of Science Communication and Information Resources, CSIR, 1972. Reprinted 2009: New Delhi. 208-24.

2. Sharma PC, Yelne MB, Dennis TJ. Database on Medicinal Plants Used in Ayurveda, Vol. 3, CCRAS. New Delhi, 2001: Reprint. 2005;3:184-205.

3. Anonymous. The Ayurvedic Pharmacopoeia of India, Part-I, Vol.III, First Edition, Govt. of India, Ministry of Health and Family welfare, Dept. of AYUSH. New Delhi. 2008;208-9. 
4. Anonymous. The Ayurvedic Formulary of India, Part-I, Second Revised English Edition, Ministry of Health and Family Welfare, Department of Indian System of Medicine and Homoeopathy. Govt. of India: New Delhi. 2003.

5. Anonymous. The Siddha Formulary of India, Part-I, First Edition, (Tamil Version) Govt. of India, Ministry of Health and Family Welfare, Department of Ayurveda, Yoga and Naturopathy, Unani, Siddha and Homoeopathy (AYUSH): 2011;46, 47,113-115,123,124.

6. Eames J, MacDaniels LH. An Introduction to Plant Anatomy. Second Edition, McGraw-Hill book company INC. London. 1947;Xi.

7. Brain and Turner. The practical Evaluation of Phytopharmaceuticals. 1975.

8. Anonymous. Quality Control Methods for Medicinal Plant Materials, World
Health Organisation. Geneva. 1998;10-11.

9. Anonymous. The Ayurvedic Pharmacopoeia of India, Part-I, Vol.VI, First Edition, Govt. of India, Ministry of Health and Family welfare, Dept. of AYUSH. New Delhi: 2008;233-42.

10. Iyengar MA. Pharmacognosy of Powdered Crude Drugs. Manipal Power Press: Manipal. 1980.

11. Sass JE. Botanical Microtechnique, Oxford and IBH Publishing co. Calcutta 1958.

12. Dymock W, Warden CJH, Hooper D. A History of the Principal Drugs of Vegetable Origin met within British India Republic. Pharmacographia Indica. Vol. I (Vivek Vihar, Delhi, India). 1995;68-9.

\section{GRAPHICAL ABSTRACT}

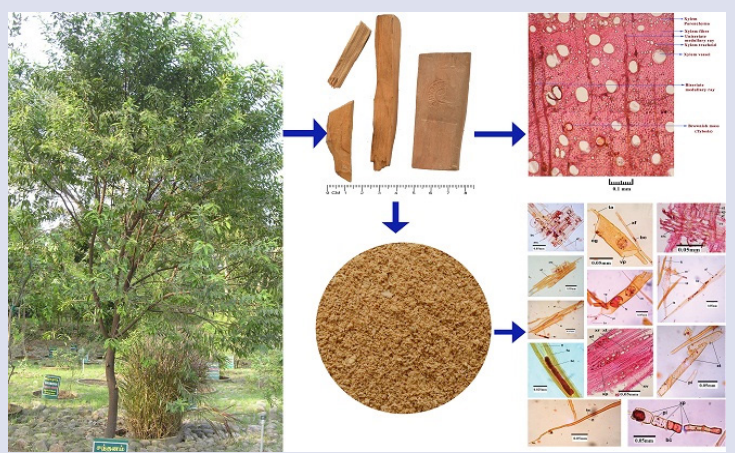

\section{SUMMARY}

- Santalum album L. (Fam. Santalaceae) is a small evergreen tree distributed in South India mainly on the Deccan plateau, especially in Mysore and Tamil Nadu.

- The heartwood is highly prized and medicinally useful; Santalum album is one of the ingredients in many Ayurvedic and Siddha formulations.

- The present study brings out macro-microscopic atlas on heartwood of medicinal plant Santalum album L.

- $\quad$ Findings of the study helpful in authentication of raw drug and standardization of Ayurvedic and Siddha formulations containing sandalwood as ingredient.

\section{ABOUT AUTHORS}

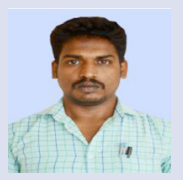

Susikumar Sundaramoorthy is a Research Scholar at Captain Srinivasa Murthy Regional Ayurveda Drug Development Institute, Chennai - 600 106, Under CCRAS, Ministry of AYUSH, Govt. of India. His doctoral research focused on developing quality standards for medicinal plants used in Ayurveda. He has worked under the ICMR project titled on "Quality Standards for Indian Medicinal Plants and preparation of monograph thereon." Has experience in the area of Pharmacognosy and Botany.

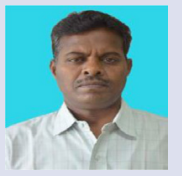

Ilavarasan Raju is an Assistant Director (S-III) in-charge at Captain Srinivasa Murthy Regional Ayurveda Drug Development Institute, Chennai - 600 106, Under CCRAS, Ministry of AYUSH, Govt. of India. He has projects in Intra Mural and Extra Mural Research Schemes. Has vast experience in the area of Pharmacology and Herbal Drug Standardization. Guiding students for Ph.D., studies of various universities.

Cite this article: Susikumar S, Nartunai G, Arunachalam C, Ilavarasan R. Macro-Microscopic Atlas on Heartwood of Santalum album L. (Sandalwood). Pharmacog J. 2018;10(4):730-3. 